\title{
Empirical Study on the Formation Mechanism of Media Effect in Chinese Stock Market
}

\author{
Wang Songshu ${ }^{1}$, Xia Xinping ${ }^{1} \&$ Li Antai $^{1}$ \\ ${ }^{1}$ School of Management, Huazhong University of Science and Technology, China \\ Correspondence: Li Antai, Huazhong University of Science and Technology, Wuhan, China. E-mail: \\ antonio.at.li@gmail.com
}

Received: April 1, 2015

Accepted: April 20, 2015

Online Published: May 22, 2015

doi:10.5539/ijbm.v10n6p168

URL: http://dx.doi.org/10.5539/ijbm.v10n6p168

\begin{abstract}
This paper investigates the formation mechanism of media effect in Chinese stock market. We prove the existence of media effect in Chinese market and examine the three hypotheses (Impediment to Trade Hypothesis, Return Continuation and Reversal Hypothesis and Investor Recognition Hypothesis) of its formation mechanism respectively. We compare the media effect in Main Board, Small and Medium Enterprise Board, and Growth Enterprise Market respectively. We find media effect is most significant in Growth Enterprise Market and the result is consistent with Impediment to Trade Hypothesis. We divide our samples into 4 quartiles and the results are consistent with Return Continuation and Reversal Hypothesis. We can not find significant relationship between analyst reports and stock return, therefore we can not prove the validity of Investor Recognition Hypothesis in Chinese market. This paper sheds light on Chinese Multi-level Capital market and extends empirical results of media effect in Chinese market.
\end{abstract}

Keywords: media effect, stock market, formation mechanism, multi-level capital market

\section{Introduction}

The so called "Media Effect", the effect of media report on capital market, has been a popular research field all over the world. Media plays a role to assemble and convey information to different audience. It has great influence on society nowadays. In financial market, media has been more and more important for investors and listed companies.

There are three hypotheses of formation mechanism of media effect: Impediment to Trade Hypothesis (ITH), Return Continuation and Reversal Hypothesis (RRH), and Investor Recognition Hypothesis (IRH). ITH states that media effect is more likely to appear in small and illiquid market. RRH argues that stock return will reverse after high volume media reports. IRH argues that lower reported stocks have higher return than higher reported stocks.

In this paper, we investigate the existence of media effect in Chinese market and examine the three hypotheses of its formation mechanism respectively. We first prove the validity of media effect in Chinese market. We find validity of ITH and RRH in Chinese market. However, we can not prove validity of IRH. We contribute to the literature in two ways: First, we extend the research of media effect and provide additional evidence in Chinese listed market. Second, we shed light on Chinese Multi-level Capital Market: Main Board, Small and Medium Enterprise Board (SME), and Growth Enterprise Market (GEM). We make comparison among different markets and provide unique evidence that GEM has more significant media effect than others.

The rest is arranged as below: Section 2 demonstrates the literature review; Section 3 exhibits research hypothesis; Section 4 shows the models and data; Section 5 shows the empirical results; Section 6 makes conclusions.

\section{Literature Review}

There is great amount of literature relating to the relationship between media and stock market. Engelberg and Parsons (2011) discover that increasing coverage of local media will improve the transaction volume. Solomon (2012) discovers that media tends to manipulate investor's behaviors by selected reporting. Media tends to report only good news to improve stock return. Liu et al. (2011) discover that media report will significantly improve IPO return. Gurun and Butler (2012) argue that slant media reporting will improve firm's value. The prior 
researches show significant relationship between media effect and stock market.

\subsection{Media Effect}

Media effect is the fact that the more media reported stock has lower return (Fang \& Peress, 2009). The results are contrast to traditional view of financial theory. There are various approaches to influence stock market by media. Financial media analyzes the market through multiple perspectives, such as selling information through buying low and selling high, slant reporting and in depth reporting. Chan (2003) discovers a great amount of drifts on the first day the firm goes public. Besides the drifts, there is huge hype in transaction volume, especially for the companies recommended by Wall Street Journal and Dow Jones News Online. Fang and Peress (2009) discover that if a company attracts higher media attention, its return will decline. In this way, information asymmetry has been released as well as risk and premium are reduced.

In all, financial media plays a role of assembling information. Therefore, it is able to influence stock prices and return by altering investor's choices by attracting investor's attention.

\subsection{Formation Mechanism of Media Effect}

Based on Fang and Peress (2009), there are three hypotheses of formation mechanism of media effect: Impediment to Trade Hypothesis, Return Continuation and Reversal Hypothesis and Investor Recognition Hypothesis.

1) Impediment to Trade Hypothesis (ITH)

The ITH is related to liquidity, stating rational investors will arbitrage through differences in prices. Therefore, price differences will no longer exist. Media effect will last long only in a friction market. Fang, Peress and Zheng (2011) study on the relationship between media attention and transaction behavior, arguing that investors have propensity to buy stock with higher media attention, given the same level of limited attention bias. The results are more significant in small and illiquid firms. Vega (2006) finds the transaction costs are the main reason for drifts after announcements. These anomalies induce higher risk to invest those companies. Therefore, investors need more risk premium.

2) Investor Recognition Hypothesis (IRH)

IRH is based on Merton's (1997) Investor Recognition Theory. Investor can not know all information about the stock in incomplete information market. Therefore, media conveys the information to more investors and expands the investor's recognition. While the recognition is lower in those unreported or uncovered stock. Those stocks are more likely to have higher risk premium. Fang and Peress (2009) argue that lower public recognition results in higher risk, therefore investors claim higher risk premium. On the other side, media coverage expands the investor recognition resulting in lower risk premium. Therefore, for those frequently reported stocks are more likely to have lower return. However, Zhang et al. (2011) do not find consistent results in Chinese market.

3) Return Continuation and Reversal Hypothesis (RRH)

RRH is based on investor's over attention. Most investors are irrational and willing pay much attention to those unexpected. Barber and Odean (2005) argue that due to investor's limited attention, investors only invest the stock they are familiar with. They do not have time to select and evaluate all the information and tend to purchase the stocks that grab their attention. Seasholes and Wu (2007) find limit-up stock attracts investor's attention and has higher purchase volume than other stocks. Rao et al. (2010) prove validity of media effect in Chinese listed market through constructing Fama-French 3-Factor Model, Carhart 4-Factor Model and Zero Arbitrage Model. And Zhang et al. argue that the results in Chinese listed market are consistent with RRH by Propensity Score Matching method and abnormal return.

\section{Hypothesis Development}

In this section, we demonstrate the hypothesis development about existence of media effect and hypotheses of its formation mechanism in Chinese market.

\subsection{Hypothesis for Media Effect in Chinese Market}

Fang and Peress (2009) investigate media effect in American market and they find the negative relationship between media coverage and stock return. Consistently, Rao et al. (2010) also prove the effect in Chinese market by Fama-French 3-Factor Model, Carhart 4-Factor Model and Zero Arbitrage Model. Under this perspective, Zhang et al. (2011) prove the existence of RRH in Chinese market by the samples from 2001 to 2008.

Based on prior researches, we derive the hypothesis below:

\section{H3-1: For Chinese listed companies, if it receives more media reports, its return will be lower.}




\subsection{Hypotheses for Formation Mechanism of Media Effect}

On April 20th, 2012, Shenzhen Stock Exchange announces regulations of GEM, attracting large amount of companies to go public and huge amount media attention. During that time, the price of GEM is going up rapidly. However, after several weeks, the price loses advantages and go sluggish since media report turn to unreported stocks. Chinese scholars have studied on media effect (Rao et al., 2010; Zhang et al., 2011). They find the existence of media effect in Chinese market.

Compare to other markets, GEM is a young and emerging market. Companies listed in GEM has lower registration requirements, lower profitability requirements and smaller management group. However, the researches of GEM are limited compared with main board. Since the companies are small and illiquid compared with those listed in Main Board, it meets the basic requirements of ITH (Fang \& Peress, 2009). According to definitions of the hypothesis and prior researches, we derive the hypothesis below:

\section{H3-2: Compared with Main Board and small and SME, if the companies in GEM receives more media} reports, it will get lower stock return.

RRH states that investor purchases large volume of attention grabbed stock and results in return reserve. Zhang et al. (2011) prove the its validity through constructing transaction volume response and calendar time combination. They find sampled volume has been enlarged. Prior to transaction date, return of the stock is positive, after the transaction date, the return reverse to negative. Based on Supply-Demand Curve in economics: When prices fall, investors will purchase at high volume; and price will also go up at the same time; However, when price is beyond its intrinsic value, the investor have less propensity to buy additional stocks. Then the transaction volume and price will fall. Media can play a role to convey the information to investors and make impact on their behaviors. In this research, we subdivide our samples into 4 quartiles and try to investigate the reversal situation before and after the media report. Based on prior research, we derive the hypothesis below:

\section{H3-3: If the company receives higher level of media reports, its stock return will go down after awards.}

IRH is based on incomplete information market, where investor can not know all the information. Therefore, media conveys the information to more investor and enlarge the investor's recognition. Investors tend to buy the stock they are familiar with or have already purchased. For those unreported stocks, investors have less propensity to buy them. Those will have high risk premium. Previously, Zhang et al. (2011) proved the invalidity of IRH in Chinese market by Propensity Score Matching method. To further examine the hypothesis, we adopt Fang and Peress's (2009) method to examine the hypothesis. Analyst reports show another way to convey information. We substitute the times of analyst reports for media reports. Therefore, we derive the hypothesis below:

\section{H3-4:If the company receives more media reports, it will have lower stock return.}

\section{Data and Model}

\subsection{Data}

We adopt data from CSMAR1 and CCER2 from 2009 to 2012 in Chinese A Share Market. We obtain 121,163 news reports from CSMAR News Data Base. We manually collect the information and assemble them into different categories. We record the times reported. Finally, we get 8443 samples. We also derive other financial data from CCER. Furthermore, we compare media effect in Main Board, SME and GEM. There are 5480 samples of main board, 2172 samples of SME and 781 samples of GEM. There are 65062 analyst reports in the whole sample.

\subsection{Variables and Models \\ 1) Stock Return (Return and Return')}

There are different research methodologies towards stock return. Solomon et al. (2012) adopt mutual fund data from CRSP data base in the period from 1998 to 2008. And Liu et al. (2011) find the relationship between media coverage and return on IPO based on financial data from Thomson Reuters. Similarly, we adopt abnormal return from over all market from CCER. We take Return for the abnormal return from the whole market and Return' for the abnormal return to the same board.

2) Media Report (Media)

Peress and Fang (2009), Dai Yiyi (2010) and many other researchers adopt similar method to evaluate the media report. They collect the times of main media report for each target firm. Ahern and Sosyura (2014) conduct the 
research on the media tone and stock return based on Factiva data in US. In this paper, we employ the similar (Note $1 \& 2$ ) method to collect data from CSMAR and manually select the report times and match each company. CSMAR contains the data from 2000 up to now. We find 121,163 news reports from 2009 to 2012 . Then we assemble and add each news to target company.

3) Analyst Report (Analyst)

According to Fang and Peress (2009), we adopt similar method to introduce analyst reports from CSMAR. We collect the number of reports from 2009 to 2012. There are 65062 reports in total. And we accumulate and match each reports to target firm. There are 8433 samples in all.

4) Control Variables

We include several control variables in to regression models: firm's size (Size), the natural logarithms of the firm's total assets. Financial leverage (LEV), the ratio of total debt to total assets; Firm's Value (T-Q) is the ratio of market value to book value; Return on Asset (ROA), the ratio of income to total assets. The definitions of variables are demonstrated in Table 1.

Table 1. Variable definitions

\begin{tabular}{ll}
\hline Variables & Definitions \\
\hline Return & Abnormal return to the whole market \\
Return' & Abnormal return to the same board \\
Media report(Media) & The times of media report. \\
Media report by quartile (Media_) & 4 quartiles for media reports. \\
Firm's size (Size) & Natural logarithm of firm's total size. \\
Analyst report(Analyst) & Times of analyst report. \\
Return to Asset (ROA) & The ratio of income to assets. \\
Firm's value (T-Q) & The ratio of market value to book value. \\
Firm's leverage (LEV) & The ratio of total debt to total firm's assets. \\
\hline
\end{tabular}

Table 2 demonstrates the quartiles of media reports. There are four quartiles of media reports. We make quartiles by the times of reports: the first quartile is between 1 to 29 , we note 1 for those companies; second quartile is between 30 to 33, we note 2 for those companies; third quartile is between 34 to 40 , we note 3 for those companies; fourth quartile is more than 40 , we note 4 for those companies.

Table 2. Quartile of media reports

\begin{tabular}{lll}
\hline Report Times & Frequencies & Quartiles \\
\hline $1-29$ & $0-25 \%$ & 1 \\
$30-33$ & $25 \%-50 \%$ & 2 \\
$34-40$ & $50 \%-75 \%$ & 3 \\
More than 40 & $75 \%-100 \%$ & 4 \\
\hline
\end{tabular}

For Hypothesis 3-1 and Hypothesis 3-2, we construct the model below:

$$
R \text { e turn } t_{t}=\alpha+\beta_{1} \text { Media }+\beta_{2} R O A+\beta_{3} L E V+\beta_{4} \text { Size }+\beta_{5} T-Q+\varepsilon
$$

For Hypothesis 3-3, we construct the model below:

$$
R \text { eturn }_{t}=\alpha+\beta_{1} \text { Analyst }+\beta_{2} R O A+\beta_{3} L E V+\beta_{4} \text { Size }+\beta_{5} T-Q+\varepsilon
$$

For Hypothesis 3-4, we construct the model below:

$$
\text { Return }_{t}=\alpha+\beta_{1} \text { Media }+\beta_{2} R O A+\beta_{3} L E V+\beta_{4} \text { Size }+\beta_{5} T-Q+\varepsilon
$$

We make regression analysis by SPSS13.0.

\section{Empirical Results}

\subsection{Descriptive Statistics}

Table 3 demonstrates the descriptive statics of media effect in Chinese listed market. 
Table 3. Descriptive statics of media effect in Chinese market

\begin{tabular}{lllllll}
\hline & Media & ROA & Size & Lev & Return & T-Q \\
\hline Samples & 8433 & 8433 & 8433 & 8433 & 8433 & 8433 \\
Minimum & 0 & 0 & 0.002 & -0.920 & -0.113 & 1.120 \\
Maximum & 492.0 & 1 & 151.1 & 0.305 & 0.095 & 250.3 \\
Mean & 10.93 & 0.154 & 17.79 & 0.218 & 0.001 & 15.20 \\
SD & 20.75 & 1.249 & 63.25 & 1.579 & 0.018 & 15.16 \\
\hline
\end{tabular}

There are 8433 samples. We find maximum media reports are 492 times and lowest is 0 . The average reports are 10.93. The average abnormal return is 0.001 .

Table 4, Table 5 Table 6 and Table 7 demonstrate the descriptive statics for the year from 2009 to 2012 respectively.

Table 4. Descriptive statics of media effect in Chinese market in 2009

\begin{tabular}{lllllll}
\hline & Media & ROA & Size & Lev & T-Q & Return \\
\hline Samples & 1689 & 1689 & 1689 & 1689 & 1689 & 1689 \\
Minimum & 0 & 0 & 1.120 & 0.002 & 9.210 & -0.047 \\
Maximum & 66.00 & 1 & 197.1 & 1.387 & 30.10 & 0.095 \\
Mean & 0.371 & 0.069 & 16.89 & 0.691 & 21.62 & 0.003 \\
SD & 3.743 & 0.429 & 14.90 & 3.792 & 1.711 & 0.016 \\
\hline
\end{tabular}

Table 5. Descriptive statics of media effect in Chinese market in 2010

\begin{tabular}{lllllll}
\hline & Media & ROA & Size & Lev & T-Q & Return \\
\hline Samples & 2038 & 2038 & 2038 & 2038 & 2038 & 2038 \\
Minimum & 0 & 0 & 11.21 & 0.002 & 1.120 & -0.069 \\
Maximum & 138.0 & 1 & 151.1 & 0.303 & 250.3 & 0.082 \\
Mean & 0.435 & 0.015 & 30.23 & 0.210 & 21.26 & 0.002 \\
SD & 6.633 & 1.249 & 250.3 & 0.166 & 20.30 & 0.017 \\
\hline
\end{tabular}

Table 6. Descriptive statics of media effect in Chinese market in 2011

\begin{tabular}{lllllll}
\hline & Media & ROA & Size & Lev & T-Q & Return \\
\hline Samples & 2314 & 2314 & 2314 & 2314 & 2314 & 2314 \\
Minimum & 0 & 0 & 15.71 & 0.007 & 1.120 & -0.113 \\
Maximum & 109.0 & 0.022 & 30.37 & 0.134 & 193.3 & 0.087 \\
Mean & 0.394 & 0.006 & 21.78 & 0.046 & 12.73 & 0.004 \\
SD & 5.882 & 0.471 & 1.484 & 0.501 & 11.55 & 0.016 \\
\hline
\end{tabular}

Table 7. Descriptive statics of media effect in Chinese market in 2012

\begin{tabular}{lllllll}
\hline & Media & ROA & Size & Lev & T-Q & Return \\
\hline Samples & 2390 & 2390 & 2390 & 2390 & 2390 & 2390 \\
Minimum & 0 & 0 & 15.73 & 0.011 & 1.120 & -0.073 \\
Maximum & 492.0 & 0.021 & 30.49 & 0.115 & 209.2 & 0.087 \\
Mean & 37.53 & 0.004 & 21.89 & 0.047 & 11.21 & -0.006 \\
SD & 21.21 & 0.109 & 1.480 & 0.495 & 10.90 & 0.019 \\
\hline
\end{tabular}


We compare media reports in from the year of 2009 to 2012. We find increasing media reports during the years. We find largest number of media report and lowest return in 2012. The results indicate media effect in Chinese market.

Then, we compare the samples in main board, SME and GEM. The descriptive statistics are in Table 8, Table 9 and Table 10 respectively.

Table 8. Descriptive statistics for main board

\begin{tabular}{llllllll}
\hline & Media & ROA & Size & Lev & Return & Return' & T-Q \\
\hline Sample & 5480 & 5480 & 5480 & 5480 & 5480 & 5480 & 5480 \\
Minimum & 0 & 0 & 0.002 & -9.210 & -0.112 & -0.117 & 1.120 \\
Maximum & 492 & 1 & 268.1 & 30.50 & 0.095 & 0.095 & 250.3 \\
Mean & 10.66 & 0.012 & 19.36 & 22.10 & 0.001 & 0.001 & 12.18 \\
SD & 22.42 & 0.067 & 69.32 & 1.783 & 0.017 & 0.017 & 13.01 \\
\hline
\end{tabular}

Table 9. Descriptive statistics for SME

\begin{tabular}{llllllll}
\hline & Media & ROA & Size & Lev & Return & Return' & T-Q \\
\hline Samples & 2172 & 2172 & 2172 & 2172 & 2172 & 2172 & 2172 \\
Minimum & 0 & -1.189 & 0.008 & 18.86 & -0.113 & -0.118 & 2.74 \\
Maximum & 116 & 2.529 & 1.293 & 26.65 & 0.095 & 0.093 & 224 \\
Mean & 11.00 & 0.057 & 0.342 & 21.28 & 0.001 & -0.001 & 19.52 \\
SD & 17.55 & 0.079 & 0.197 & 0.815 & 0.019 & 0.018 & 15.97 \\
\hline
\end{tabular}

Table 10. Descriptive statistics for GEM

\begin{tabular}{llllllll}
\hline & Media & ROA & Size & Lev & Return & Return' & T-Q \\
\hline Samples & 781 & 781 & 781 & 781 & 781 & 781 & 781 \\
Minimum & 0 & -0.437 & 0.011 & 19.49 & -0.105 & -0.110 & 4.33 \\
Maximum & 80 & 0.279 & 0.764 & 22.57 & 0.087 & 0.089 & 150 \\
Mean & 12.57 & 0.061 & 0.176 & 20.75 & -0.003 & -0.004 & 24.32 \\
SD & 16.21 & 0.038 & 0.125 & 0.541 & 0.019 & 0.018 & 19.65 \\
\hline
\end{tabular}

In Table 8 , we find the average number of media report is 11.00 , close to the total sample. The abnormal return of total market average is 0.001 , while abnormal return of Main Board is -0.001 . In Table 10, we find the average report times is 12.57 for GEM, higher than that in other market. The results show GEM attracts higher media attention. The abnormal return to over all market is -0.003 and abnormal return to GEM is -0.004 , both of them are lower than those in Main Board and SME.

We demonstrate the descriptive statistic for quartile in Table 11. We delete those with 0 report record. We collect 2414 samples in all. The average of first quartile is 25.87 , its abnormal return is -0.009 ; while the average of last quartile is 60.38 and its abnormal return is -0.026 .

Table 11. Descriptive statistics for media report quartile

\begin{tabular}{lllll}
\hline Variables & 1 & 2 & 3 & 4 \\
\hline Media & 25.87 & 31.29 & 36.51 & 60.38 \\
Return & -0.009 & -0.006 & -0.006 & -0.026 \\
ROA & 0.028 & 0.037 & 0.038 & 0.038 \\
LEV & 0.455 & 0.438 & 0.476 & 0.557 \\
Size & 10.24 & 9.610 & 10.86 & 15.20 \\
T-Q & 21.22 & 21.70 & 21.89 & 22.81 \\
Sample & 562 & 678 & 616 & 560 \\
\hline
\end{tabular}

We also conduct multi-linear test and $\mathrm{T}$ test of independent sample, the results are not contradict to our prior 
hypotheses.

\subsection{Multiple Regression Analysis}

1) Media Effect in Chinese Market

Table 12 shows the multi regressions on media effect in Chinese market. We find significant negative relationship between media report and stock return. Our results are consistent with Fang and Peress (2009). We show media effect exists in Chinese market.

Table 12. Regression on media effect in Chinese market

\begin{tabular}{ll}
\hline Variables & Coefficients \\
\hline Media & $-0.157 * * *$ \\
ROA & 0.058 \\
LEV & -0.056 \\
SIZE & $0.062 * * *$ \\
T-Q & $0.080^{* * *}$ \\
Intersection & $-0.015^{* * *}$ \\
Samples & 8433 \\
$\mathrm{R}^{2}$ & 0.034 \\
Note. “***”, “**”, “*”are significance level at $1 \%, 5 \%$ and $10 \%$ respectively.
\end{tabular}

\section{2) Empirical Test for ITH}

In Table 13, we find significant negative relationship between media report and stock abnormal return. A company with higher media reports has lower return. Besides, we find firm's size has negative correlation between media reports at $1 \%$ significance level. The larger size of the company, the higher number of report. From the perspectives of different boards, we find differences in $\mathrm{R}$ squares, although all the coefficients are negative at $1 \%$ significance level. We find $\mathrm{R}$ square of GEM is 0.123 , which is significant higher than that in Main Board of 0.024 and in SME of 0.066 respectively. The results demonstrate that media effect is more significant in GEM and are consistent with Fang and Peress's (2009) conclusions.

Table 13. Regression for ITH

\begin{tabular}{llll}
\hline Variables & Main Board & SME & GEM \\
\hline Media & $-0.106^{* * *}$ & $-0.024^{* * *}$ & $-0.345^{* * * *}$ \\
ROA & 0.007 & 0.028 & $0.123^{* * *}$ \\
LEV & -0.016 & $0.064^{* *}$ & 0.010 \\
SIZE & $0.027^{*}$ & 0.018 & $0.074^{* *}$ \\
T-Q & $0.112^{* * *}$ & $0.057^{* *}$ & -0.031 \\
Intersection & $-0.006^{* * *}$ & -0.009 & $-0.056^{* *}$ \\
Samples & 5480 & 2172 & 781 \\
$\mathrm{R}^{2}$ & 0.024 & 0.066 & 0.123 \\
\hline
\end{tabular}

\section{3) Empirical Test for RRH}

Table 14 demonstrates the regression results for RRH by 4-quartiles method. We find significant negative relationship between media reports and stock abnormal return. The results are consistent with RRH (Zhang et al., 2011). Zhang et al. (2010) prove the validity of this hypothesis in Chinese market by transaction volume and abnormal volatility of transaction. While, we adopt abnormal return and obtain consistent results. 
Table 14. Regressions for RRH

\begin{tabular}{ll}
\hline Variables & Coefficients \\
\hline Media_- & $-0.171^{* * *}$ \\
ROA & 0.052 \\
LEV & -0.051 \\
T-Q & $0.058^{* * *}$ \\
Size & $0.075^{* * *}$ \\
Intersection & -0.013 \\
Samples & 8433 \\
$\mathrm{R}^{2}$ & 0.039 \\
\hline
\end{tabular}

\section{4) Empirical Test for IRH}

In Table 15, we substitute analyst reports for media reports to conduct regressions. After substitution, we can not find significant relationship between analyst reports and abnormal return. We can not prove the validity of IRH. The results are also consistent with Zhang et al. (2011).

Table 15. Regression for investor recognition hypothesis

\begin{tabular}{ll}
\hline Variables & Coefficients \\
\hline Analyst & -0.006 \\
ROA & 0.027 \\
LEV & -0.030 \\
T-Q & 0.034 \\
Size & 0.029 \\
Intersection & -0.010 \\
Samples & 8433 \\
$\mathrm{R}^{2}$ & 0.010 \\
\hline
\end{tabular}

\subsection{Robust Test}

In Table 16, we conduct robust test by replace abnormal return on the whole market for the abnormal return on the same market. We still find significant negative relationship between media reports and stock return. Our results are consistent with prior researches.

Table 16. Regression on Media Effect in Chinese Market

\begin{tabular}{ll}
\hline Variables & Coefficients \\
\hline Media & $-0.088^{* * *}$ \\
ROA & 0.076 \\
LEV & -0.069 \\
SIZE & $0.075^{* * *}$ \\
T-Q & $0.044^{* * *}$ \\
Intersection & $-0.019 * * *$ \\
Samples & 8433 \\
$\mathrm{R}^{2}$ & 0.013 \\
\hline
\end{tabular}

In Table 17, we show the results of robust test of ITH. We substitute abnormal return to the same board for abnormal return to the whole market. We find significant negative relationship between media reports and abnormal return across all sub groups. Specifically, we find coefficients of GEM is significant higher than that of Main Board and SME. And its R square is higher than that of other markets. The results show media effect is more significant in small and illiquid firms. 
Table 17. Robust Test for Impediment-to-Trade Hypothesis

\begin{tabular}{llll}
\hline Variables & Main Board & SME & GEM \\
\hline Media & $-0.090^{* * *}$ & $-0.043^{*}$ & $-0.135^{* * *}$ \\
ROA & 0.017 & 0.030 & $0.123^{* * *}$ \\
LEV & -0.248 & $0.066^{* *}$ & 0.013 \\
SIZE & $0.036^{* *}$ & 0.010 & $0.071^{*}$ \\
T-Q & $0.111^{* * *}$ & 0.032 & -0.055 \\
Intersections & $-0.008^{* * *}$ & -0.008 & $-0.055^{* *}$ \\
Samples & 5470 & 2172 & 781 \\
$\mathrm{R}^{2}$ & 0.022 & 0.008 & 0.031 \\
\hline
\end{tabular}

Table 18 shows the results of robust test for RRH by similar method. We find significant negative relationship between media report and stock return at $1 \%$ level. The results are consistent with our prior research.

Table 18. Robust test of RRH

\begin{tabular}{ll}
\hline Variables & Coefficients \\
\hline Media_ & $-0.098^{* * *}$ \\
ROA & 0.073 \\
LEV & -0.066 \\
T-Q & $0.073^{* * *}$ \\
Size & $0.042^{* * *}$ \\
Intersection & $-0.018^{* * *}$ \\
Samples & 8433 \\
$\mathrm{R}^{2}$ & 0.015 \\
\hline
\end{tabular}

Table 19 shows robust test for IRH. We can not find significant relationship between analyst report and stock return. Therefore, we can not prove validity of IRH in Chinese market. The results are consistent with prior research.

Table 19. Robust test for IRH

\begin{tabular}{ll}
\hline Variables & Coefficients \\
\hline Analyst & -0.016 \\
ROA & 0.061 \\
LEV & -0.056 \\
T-Q & 0.062 \\
Size & 0.056 \\
Intersection & $-0.016^{* * *}$ \\
Samples & 8433 \\
$\mathrm{R}^{2}$ & 0.007 \\
\hline
\end{tabular}

\section{Conclusions}

This paper examines the formation mechanism of media effect in Chinese market by investigating the relationship between media report and stock abnormal returns. And we examine hypotheses of formation mechanism of media effect in Chinese market. We find existence of media effect in Chinese market. We find significant negative relationship between media report and stock abnormal return across the samples. We compare media effect in Main Board, SME and GEM respectively and it is most significant in GEM. Therefore, we prove validity of ITH in Chinese market. We also prove the validity of RRH by making four quartiles for media report and discover the significant negative relationship between media report and abnormal return. While we can not find significant relationship between analyst report and stock abnormal return, we can not prove the validity of IRH in Chinese market.

We contribute the literature by extending the research of media effect and provide additional evidence in Chinese listed market. Also, we shed light on the research in Chinese Multi-level Capital market. We make comparison 
among different boards and provide unique evidence that GEM has most significant media effect than other boards. We will extend this research to other aspects, including new technology in media reporting, other measurements in stock return in future.

\section{References}

Barber, B., \& Terrance, O. (2008). All that Glitters: The Effect of Attention and News on the Buying Behavior of Individual and Institutional Investors. Review of Financial Studies, 21, 785-818. http://dx.doi.org/10.1093/rfs/hhm079

Chan, W. S. (2003). Stock Price Reaction to News and No-News: Drift and Reversal after Headlines. Journal of Financial Economics, 70, 223-260. http://dx.doi.org/10.1016/S0304-405X(03)00146-6

Engelberg, J., \& Christopher, A. P. (2011). The Causal Impact of Media in Financial Markets. Journal of Finance, 66, 67-97. http://dx.doi.org/10.1111/j.1540-6261.2010.01626.x

Fang, L. H., \& Joel, P. (2009). Media coverage and the cross-section of stock returns. Journal of Finance, 64, 2023-2052. http://dx.doi.org/10.1111/j.1540-6261.2009.01493.x

Gurun, U. G., \& Alexander, W. B. (2012). Don't Believe the Hype: Local Media Slant, Local Advertising, and Firm Value. Journal of Finance, 67, 561-598. http://dx.doi.org/10.1111/j.1540-6261.2012.01725.x

Liu, L., Ann, S., \& Yong, Z. (2011). The Role of Media in Initial Public Offerings. Working paper. DePaul University and Hong Kong University of Science \& Technology.

Merton. (1987). A Simple Model of Capital Market Equilibrium with Incomplete Information. Journal of Finance, 162(3), 2-29. http://dx.doi.org/10.1111/j.1540-6261.1987.tb04565.x

Rao, Y. L., Peng, D. F., \& Chen, D. C. (2010). Does Media Attention Cause abnormal return? Evidence from China's Stock Market. System Engineering Theory and Practice, 30(2), 287-297.

Seasholes \& Wu, G. J. (2007). Predictable Behavior, Profit and Attention. Journal of Empirical Finance, 14, 590-610. http://dx.doi.org/10.1016/j.jempfin.2007.03.002

Solomon, D. H., Eugene, F. S., \& Denis, S. (2014). Winners in the Spotlight: Media Coverage of Fund Holdings as a Driver of Flows. Journal of Financial Economics, 113(1), 53-72. http://dx.doi.org/10.1016/j.jfineco.2014.02.009

Vega, C. (2006). Stock Price Reaction to Public and Private Information. Journal of Financial Economics, 82, 103-133. http://dx.doi.org/10.1016/j.jfineco.2005.07.011

Zhang, Y. H., Wan, D. F., \& Fu, L. M. (2011). The Media Effect of Stock Market. Financial Research, (8), 143-156.

\section{Note}

Note 1. CCER is China Security Market Database System created by China Center of Economic Research and Sinoinfo Information Services. It is the authoritative database in China.

Note 2. CSMAR is short for China Stock Market and Accounting Research Database. It offers data on the China stock markets and the financial statements of Chinese listed companies. It is the authoritative database in China.

\section{Copyrights}

Copyright for this article is retained by the author(s), with first publication rights granted to the journal.

This is an open-access article distributed under the terms and conditions of the Creative Commons Attribution license (http://creativecommons.org/licenses/by/3.0/). 